\title{
COMO PESQUISAR O PERFIL PATENTÁRIO DE UM FÁRMACO: O CASO EFAVIRENZ
}

\author{
Jaqueline Mendes Soares* \\ Instituto Nacional da Propriedade Industrial, Praça Mauá, 7, 20081-240 Rio de Janeiro - RJ / Instituto de Medicina Social, \\ Universidade Estadual do Rio de Janeiro, Rua São Francisco Xavier, 524, 20550-900 Rio de Janeiro - RJ, Brasil \\ Marilena Cordeiro Dias Villela Correa \\ Instituto de Medicina Social, Universidade Estadual do Rio de Janeiro, Rua São Francisco Xavier, 524, 20550-900 Rio de Janeiro \\ - RJ, Brasil
}

Recebido em 25/5/09; aceito em 30/11/09; publicado na web em 8/4/10

\begin{abstract}
HOW TO DETERMINE THE PATENT PROFILE OF A DRUG: A CASE STUDY OF EFAVIRENZ. The importance of the patent system for researchers, especially in chemistry and related areas, is undeniable. In this context, this work aims at guiding the search in major search engines of patents, in order to map the patents related to a specific chemical compound and identify the material that each patent document protects. In this case study, it was performed a search for the drug efavirenz to demonstrate how to conduct a literature search in patents databases and to map patent applications at national and international levels.
\end{abstract}

Keywords: patent; efavirenz; patent databases.

\section{INTRODUÇÃO}

No Brasil, o pouco conhecimento de temas relativos à patente por parte do nosso setor produtivo, universidades, centro de pesquisas e até mesmo por inventores isolados, pode ser evidenciado pela falta de visão tanto de empresas quanto do inventor nacional em depositar pedidos de patente. Mesmo se artigos científicos são publicados em grande volume em periódicos reconhecidos em nível mundial por autores nacionais, a quantidade de patentes depositadas pelos centros de pesquisa e universidades, desenvolvidas pelos pesquisadores, ainda é insuficiente e desproporcional à produção de ideias e artigos. ${ }^{1}$

Observa-se que o interesse na obtenção de patentes ainda não se integra ao modelo dominante de reconhecimento ao trabalho científico e às decisões de fomento à pesquisa. É preciso frisar que a publicação de artigos e a divulgação do conhecimento em reuniões científicas, itens importantes na avaliação da produtividade do pesquisador podem pôr a perder a característica de novidade e atividade inventiva de uma invenção. Além disso, a dificuldade dos pesquisadores brasileiros se deve, em grande parte, a problemas operacionais, tais como a falta de informação, descuido, inexistência ou despreparo dos escritórios especializados em patentes e ao alto custo do depósito de patentes, tendo em vista que o pedido de patente deve ser depositado em cada um dos países em que se deseja a proteção. ${ }^{2}$

A patente é a forma mais definitiva de proteção da propriedade intelectual, visto que o produto protegido por patente não pode ser copiado, produzido e nem comercializado por terceiros. Além disso, a proteção legal garantida pela propriedade industrial é também um vetor de aprendizado tecnológico de um país, e a quantidade de depósitos de pedidos de patente reflete o grau de desenvolvimento econômico do mesmo. Contudo, para garantir a eficácia deste sistema faz-se necessário que a comunidade científica conheça a legislação e as regras que regem a propriedade intelectual de modo a evitar a situação de violação de direitos, assim como para aprimorar o conhecimento acumulado que constitui incentivo a novas invenções e inovações no campo científico tecnológico. ${ }^{3}$

O presente trabalho teve como objetivos: contribuir para o aprendizado da busca de patentes em bancos de dados de patentes;

*e-mail: jsoares@inpi.gov.br mapear as patentes relacionadas a um determinado composto químico; identificar a matéria que está protegida por cada documento de patente. Para tal, foi realizado, do ponto de vista metodológico, um estudo de caso: a determinação do perfil patentário do medicamento anti-retroviral efavirenz. A escolha deste medicamento está em função da sua relevância terapêutica no tratamento da AIDS e, também, por ter sido o primeiro medicamento, de especial interesse para o Ministério da Saúde do Brasil, a ter o licenciamento compulsório decretado no país. ${ }^{4}$

\section{SISTEMA DE PATENTES}

O primeiro passo para o depósito de um pedido de patente é a realização de uma busca de documentos do estado da técnica, ou seja, qualquer tipo de documento tornado acessível ao público de forma oral, escrita, por uso ou qualquer outro meio, no Brasil ou no exterior. Essa busca deve avaliar se a invenção descrita no pedido apresenta novidade, atividade inventiva e aplicação industrial - os requisitos exigidos por lei para a concessão de uma patente. ${ }^{5}$

O Brasil concede dois tipos de patentes - as de invenção (PI), com maior conteúdo tecnológico e as de modelo de utilidade (MU), geralmente aperfeiçoamentos sobre dispositivos já existentes. O número que os pedidos de patente recebem ao dar entrada no INPI é formado por conjuntos de letras e algarismos. As duas primeiras letras maiúsculas correspondem à natureza da patente, e são: PI para patente de invenção e MU para modelo de utilidade. Em seguida, vem o número do pedido, que é composto de sete dígitos. Para patente de invenção, os dois primeiros algarismos correspondem ao ano de depósito do pedido e os cinco seguintes são atribuídos em ordem cronológica de depósito no INPI. Por exemplo, o PI9401234 foi depositado no ano de $1994 .{ }^{6}$

Um pedido de patente é constituído por diferentes partes: relatório descritivo, reivindicações e resumo. O relatório descritivo deve apresentar o estado da técnica e delimitar a invenção que se pretende proteger, descrevendo-a de modo a poder ser reproduzida por um técnico no assunto, sendo que, muitas vezes se faz necessário apresentar exemplos, gráficos, desenhos e fluxogramas. As reivindicações compõem a parte mais importante de um pedido de patente, pois delimitam a matéria que se deseja proteger. $\mathrm{O}$ resumo deve ser 
redigido de tal maneira que possa fornecer informações para uma análise preliminar da matéria descrita no pedido de patente. ${ }^{7}$

\section{BUSCA DE PATENTES EM BASES DE DADOS}

O pesquisador deve fazer busca em documentos publicados, tais como livros, artigos e patentes, antes de iniciar a pesquisa e antes de redigir o depósito do pedido de patente em escritório de propriedade industrial. Assim, o primeiro passo em um projeto de pesquisa deve ser a revisão bibliográfica da literatura pertinente na área de atuação, para conhecer o estado da arte, ou seja, se o tema do projeto vem sendo estudado por outros, bem como os pontos positivos e negativos já encontrados. Dessa maneira, o pesquisador "não irá reinventar a roda", ou seja, irá eliminar etapas que outros já realizaram. Caso não faça essa busca, gastará tempo e dinheiro para chegar a conclusões já alcançadas por terceiros.

Atualmente existem diversas bases de patentes, cada uma com características particulares. Nesse sentido, elas podem conter documentos de patentes de diversos países, como é o caso da base de patentes do Escritório Europeu de Patentes (EPO) ou somente documentos do país que elaborou a base, por exemplo, a base do INPI só possui documentos de patente brasileiros. Além disso, cada uma das bases de dados disponibiliza possibilidades diferentes de realizar a busca e apresentar os resultados. A maior parte das bases permite busca a partir dos seguintes campos: número da patente, data de depósito, nome do inventor, nome do depositante, palavra-chave no título e/ou resumo.

Com relação ao andamento do processo de exame do pedido de patente, algumas bases possibilitam o acompanhamento on-line de todo processo do pedido depositado (exigências etc.), enquanto outras, disponibilizam apenas o resultado final da publicação do pedido e/ ou da concessão da patente.

Em suma, a escolha da base de patentes a ser utilizada é fundamental, uma vez que dela dependerá o tipo de dados que se poderá obter: em alguns casos, o pesquisador terá acesso apenas aos dados bibliográficos, como título e resumo; em outros o acesso é franqueado ao documento integral, de maneira digitalizada ou em formato pdf. No Brasil, o INPI disponibiliza a busca de documentos de patente em papel, on-line, CD-ROM ou DVD. ${ }^{8}$

No que concerne à busca on-line, que vai abranger uma diversidade muito maior de documentos de patentes, esta pode ser realizada através de bancos de dados comerciais ou bases de dados gratuitas. Os bancos de dados comerciais possibilitam uma recuperação de documentos mais precisa pelo fato de utilizarem ferramentas de busca mais elaboradas que aquelas disponíveis nas bases gratuitas. Contudo, exigem um treinamento mais aprofundado, além do preço do acesso a cada base ser cobrado em relação ao tempo de acesso e ao volume de informação recuperada.

Dentre os diversos bancos de dados comerciais disponíveis os mais utilizados são o DIALOG, ${ }^{9}$ que permite acesso a cerca de 600 bases de dados em diversas áreas do conhecimento; o STN (The Scientific \& Technological Information Network), ${ }^{10}$ que é especializado na área de química e de patentes e o SciFinder, ${ }^{11}$ que é formado por diversas bases de dados principalmente o Chemical Abstract Service (CAS).

Já a busca on-line em bases de dados gratuitas pode ser realizada nos sites dos escritórios de patente de diversos países, os quais se encontram relacionados na Tabela $1 .^{12}$

\section{ESTUDO DO CASO EFAVIRENZ}

$\mathrm{Na}$ pesquisa para coleta de informações apresentadas a seguir, foram utilizados o Merck Index, ${ }^{13}$ a base de dados Scifinder Scholar e as bases de dados do INPI e EPO.

A pesquisa foi iniciada pela busca do nome efavirenz no Merck Index, onde foi possível recuperar as seguintes informações: o seu Register Number ( $\mathrm{RN}=154598-52-4)$, os números dos depósitos dos pedidos de patentes europeu (EP582455) e americano (US5519021), como sendo os primeiros documentos de patente para a proteção deste princípio ativo. O RN é uma descrição única dada para cada substância

Tabela 1. Bases de dados para a busca de informação patentária

\begin{tabular}{|c|c|c|}
\hline Base de patentes & Endereço eletrônico & Particularidades \\
\hline $\begin{array}{l}\text { Escritório brasileiro } \\
\text { (INPI) }\end{array}$ & http://www.inpi.gov.br & $\begin{array}{l}\text { A busca pode ser efetuada utilizando-se os dados bibliográficos: depositante, inventores, data de } \\
\text { depósito, título, classificação internacional, prioridade (número, país e data), entre outros ou por } \\
\text { palavras-chave no título ou resumo. }\end{array}$ \\
\hline $\begin{array}{l}\text { Escritório europeu } \\
\text { (EPO) }\end{array}$ & http://ep.espacenet.com & $\begin{array}{l}\text { É possível recuperar as patentes correspondentes (família de patentes). Possibilita a busca através de } \\
\text { dados bibliográficos ou palavras-chave no título e resumo. }\end{array}$ \\
\hline $\begin{array}{l}\text { Escritório norte- } \\
\text { americano (USPTO) }\end{array}$ & http://www.uspto.gov & $\begin{array}{l}\text { Permite a busca em duas bases: a de patentes concedidas ( } 1976 \text { - texto completo e } 1790 \text { - digitaliza- } \\
\text { dos) e a de pedidos publicados (a partir de 15/3/2001). Pode ser feita no documento completo ou em } \\
\text { campos específicos (título, resumo, reivindicações e relatório descritivo) através de palavras-chave. }\end{array}$ \\
\hline $\begin{array}{l}\text { Escritório japonês } \\
\text { (JPO) }\end{array}$ & http://www.ipdl.jpo.gp.jp & $\begin{array}{l}\text { Disponibiliza a tradução integral em inglês dos documentos de patente japonês. A busca é realizada } \\
\text { somente nos dados bibliográficos e pelo número do documento da patente. }\end{array}$ \\
\hline $\begin{array}{l}\text { Escritório canadense } \\
\text { (OPIC) }\end{array}$ & http://opic.gc.ca & $\begin{array}{l}\text { Permite a busca em documentos de patente canadenses a partir de } 1920 \text { através dos dados bibliográfi- } \\
\text { cos e a partir de agosto de } 1978 \text { pelos dados bibliográficos, resumos e reivindicações. }\end{array}$ \\
\hline Escritório indiano & http://pk2id.delhi.nic.in & $\begin{array}{l}\text { Disponibiliza os dados bibliográficos de documentos de patente de diversos países, assim como a } \\
\text { família de patentes. Busca-se pelos dados bibliográficos e número do documento de patente. }\end{array}$ \\
\hline $\begin{array}{l}\text { Pedidos de } \\
\text { patentes via Patent } \\
\text { Cooperation Treat } \\
\text { (PCT) }\end{array}$ & $\begin{array}{l}\text { http://www.wipo.int/ipdl/en/ } \\
\text { index.jsp }\end{array}$ & $\begin{array}{l}\text { Contém os documentos completos dos pedidos de patente depositados via PCT, a busca pode ser } \\
\text { realizada pelos dados bibliográficos. }\end{array}$ \\
\hline $\begin{array}{l}\text { Food Drugs } \\
\text { American (FDA) }\end{array}$ & http://www.fda.gov.br & $\begin{array}{l}\text { São recuperados os números dos documentos de patente americanas relativas a medicamentos regis- } \\
\text { trados no FDA. Busca-se pelo nome do princípio ativo, depositante e marca do medicamento. }\end{array}$ \\
\hline SciFinder Scholar ${ }^{11}$ & $\begin{array}{l}\text { Universidades públicas } \\
\text { e centros de pesquisa } \\
\text { brasileiros (gratuito). }\end{array}$ & O sistema de busca permite a pesquisa por palavra-chave, autor, estrutura química, entre outras. \\
\hline
\end{tabular}


química e cada variação na molécula gera um número diferente de registro. As informações recuperadas no Merck Index para o efavirenz estão resumidas na ficha técnica da Figura 1.

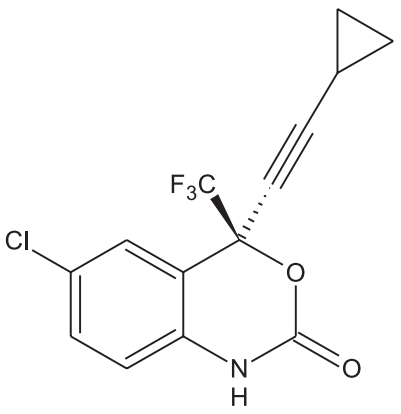

\section{RN: 154598-52-4}

Nome Químico: (4S)-6-cloro-4-(ciclopropiletil)1,4-dihidro-4-(trifluorometil)-2H-3,1-benzoxazin-2-ona

\section{Sinônimos: DMP266; L 743726 e Sustiva}

\section{Primeiros documentos de patente:EP582455 e US5519021}

Figura 1. Dados técnicos do efavirenz recuperados no Index Merck

A etapa seguinte consistiu na consulta à base de dados do escritório europeu a partir do número do documento EP582455, recuperado no Merck Index. Através desta consulta verificou-se que os documentos EP582455 e US5519021 são membros da mesma família de patentes e que a empresa Merck \& Co INC (US) depositou o documento EP582455 em 03/08/1993, tendo como documentos de prioridade os documentos americanos US054805 de 27/04/1993 e US926607 de 07/08/1992. O termo família de patentes é o conjunto de documentos depositados nos vários países com base no mesmo documento de prioridade e o direito de prioridade é uma salvaguarda dada ao inventor, por um prazo de 12 meses, que depositou seu pedido em um dos países membros da Convenção da União de Paris (CUP).

$\mathrm{Na}$ família de patentes recuperada na base de dados do escritório europeu não consta nenhum documento brasileiro correspondente para o efavirenz. Com os números dos documentos de prioridade foi realizada busca avançada na base de patentes do INPI, no campo documento de prioridade, para verificar se existiria um documento de patente brasileiro correspondente à EP582455. Após a consulta, foi recuperado o pedido de patente pipeline PI1 100250-6, depositado no Brasil em 09/04/1997, cuja patente foi concedida em 03/08/1999 e irá expirar em 21/05/2013. Assim, o princípio ativo efavirenz não está em domínio público no Brasil. As informações obtidas com as estratégias de busca descritas acima estão representadas na Figura 2.

\begin{tabular}{|c|c|c|}
\hline $\begin{array}{l}\text { Consulta ao Index Merck pelo nome do } \\
\text { fármaco efavirenz. }\end{array}$ & & $\begin{array}{l}\mathrm{N}^{\circ} \text { do documento de patente brasileiro, } \\
\text { PI1100250-6, que protege a molécula do } \\
\text { efavirenz no Brasil. }\end{array}$ \\
\hline$\downarrow$ & & \\
\hline $\begin{array}{l}\text { Números dos documentos de patente } \\
\text { que protegem o efavirenz: EP58245 e } \\
\text { Us551902. }\end{array}$ & & $\begin{array}{l}\text { Consulta ao banco de dados do INPI } \\
\text { pelo documento de prioridade US551902. }\end{array}$ \\
\hline$\downarrow$ & & $\uparrow$ \\
\hline $\begin{array}{l}\text { Consulta ao banco de dados do } \\
\text { escritório europeu pelo } n^{\circ} \text { do documento } \\
\text { EP582455. }\end{array}$ & $\longrightarrow$ & $\begin{array}{l}\text { Nome do depositante, } n^{\circ} \text { do documento } \\
\text { de prioridade e família de patentes. }\end{array}$ \\
\hline
\end{tabular}

Figura 2. Estratégias de busca realizadas

Com o objetivo de obter o número de documentos de patente relacionados ao efavirenz foi realizada uma nova busca na base de dados Scifinder Scholar ${ }^{\circledR}$, em 26/12/2008. Partindo do RN=154598-
52-4 foram obtidas 1719 referências bibliográficas. Após a triagem destas 1719 referências bibliográficas, foram identificados 408 documentos de patente relativos ao efavirenz. Com os números de identificação destes documentos foi feita busca na base de dados do escritório europeu. Em seguida foi realizada a leitura dos respectivos quadros reivindicatórios constantes dos documentos de patentes. Após a leitura observou-se que em 88 documentos de patente a palavra efavirenz (e/ou seus sinônimos) aparece apenas no relatório descritivo e não no quadro reivindicatório. Desse modo, é possível afirmar que dos 408 documentos recuperados, 320 efetivamente reivindicam o princípio ativo efavirenz.

Após a leitura do quadro reivindicatório de cada um dos 320 pedidos de patentes, foi feito um mapeamento tecnológico dos depósitos baseado em 7 categorias de proteção, a saber: composição farmacêutica, tecnologia farmacêutica, método de tratamento, formas polimórficas, processo de síntese do efavirenz e seus análogos, biotecnologia e outros. Após a exclusão de 34 documentos relativos à categoria outros e do primeiro documento de patente do efavirenz (EP582455) foram recuperados 285 documentos (Tabela 2). Os dados da Tabela 2 mostram que a maioria das patentes de invenção reivindicam composições farmacêuticas contendo o efavirenz, seguida de métodos terapêuticos para o tratamento do vírus HIV, biotecnologia, tecnologia farmacêutica, novos processos de síntese do efavirenz e formas polimórficas do mesmo.

Tabela 2. Distribuição dos documentos de patentes referentes ao efavirenz

\begin{tabular}{lcc}
\hline Seção & $\mathrm{N}^{\circ}$ de documentos & Porcentagem $(\%)$ \\
\hline Composição farmacêutica & 134 & 47,02 \\
Método terapêutico & 55 & 19,29 \\
Biotecnologia & 44 & 15,44 \\
Tecnologia farmacêutica & 34 & 11,93 \\
Processo de síntese & 11 & 3,86 \\
Formas polimórficas & 7 & 2,46 \\
\hline
\end{tabular}

A Figura 3 mostra os países dos principais depositantes que desenvolveram invenções relacionadas ao efavirenz, onde se verifica que a maioria dos documentos é oriunda de pedidos depositados via PCT, seguido pelos de origem americana, européia, japonesa e outros países, respectivamente.

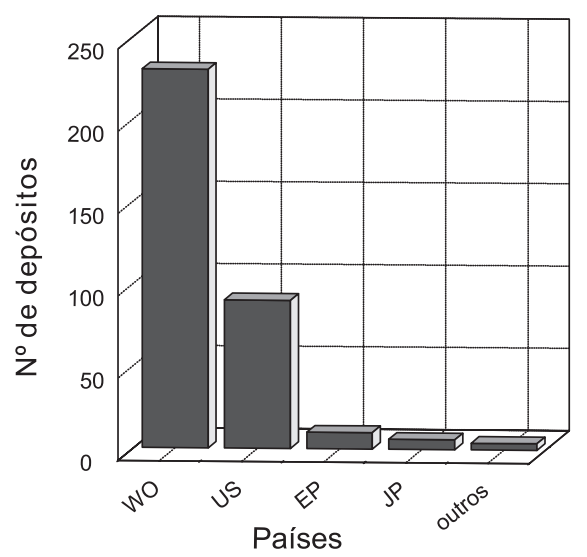

Figura 3. Número de pedidos de patente depositados por países para o efavirenz.

\section{CONCLUSÃO}

As informações contidas nos documentos de patente representam uma fonte de informação indispensável tanto à pesquisa quanto ao desenvolvimento tecnológico de um país. Por isso, a disseminação do 
conhecimento sobre patentes no âmbito das universidades e centros de pesquisa é de extrema importância à educação tecnológica do Brasil.

Apesar de existirem diversos sites que possibilitam a busca e a recuperação de documentos de patente, verificar se determinado composto químico está protegido por patente não é uma tarefa simples e exige do pesquisador um conhecimento mínimo acerca das regras do sistema de patentes.

Através da estratégia de busca, em base de dados gratuitas, adotada no presente estudo para mapear o perfil patentário da molécula do efavirenz foi possível identificar o patenteamento no âmbito nacional e internacional, delinear os principais detentores dos direitos patentários, verificar os principais países depositantes, bem como traçar um perfil da matéria a ser protegida. Sendo assim, verificou-se que o efavirenz se encontra protegido por patente no Brasil através de patente pipeline ou patente de revalidação.

\section{REFERÊNCIAS}

1. Macedo, M. F.; Figueira Barbosa, A. L.; Patentes, Pesquisa \& Desenvolvimento - Um Material de Propriedade Industrial, $1^{\mathrm{a}}$ ed., FIOCRUZ: Rio de Janeiro, 2000.

2. Macedo, M. F. G.; Muller, A. C. A.; Moreira, A. C.; Patenteamento em Biotecnologia, $1^{a}$ ed., EMBRAPA: Brasília, 2001.
3. Barbosa, D. B.; Uma Introdução à Propriedade Intelectual, $2^{\mathrm{a}}$ ed., Lúmen Júris: Rio de Janeiro, 2003; Cassier, M.; Corrêa, M.; Rev. Eletr. Com. Inf. Inov. Saúde 2007, 1, 83.

4. Brasil, Decreto $\mathrm{N}^{\circ}$ 6.108, de 04 de maio de 2007. Concede Licenciamento compulsório, por Interesse Público, de Patentes referentes ao efavirenz, para fins de Uso Público Não-Comercial.

5. Januzzi, A. H. L.; Dissertação de Mestrado, Centro Federal de Educação Tecnológica Celso Succkow da Fonseca, Brasil, 2007.

6. Barroso W. B. G.; Dissertação de Mestrado, Universidade Federal do Rio de Janeiro, Brasil, 1999.

7. Barros, C. E.; Manual de Direito da Propriedade Intelectual, $1^{\text {a }}$ ed., Evocati: Aracaju, 2007.

8. http://www.inpi.gov.br, acessada em Dezembro 2008.

9. http://dialog.com, acessada em Dezembro 2008.

10. http://www.stn-international.de, acessada em Dezembro 2008.

11. Ridley, D.; Information Retrieval Scifinder and Scifinder Scholar, $1^{\mathrm{a}}$ ed., John Wiley \& Sons, 2002.

12. Oliveira, L. G.; Suster R.; Pinto A. C.; Ribeiro N. M.; Silva R. B.; Quim. Nova 2005, 28, 236.

13. The Merck Index an encyclopedia of chemicals, drugs and biologicals, $14^{\text {th }}$ ed., Merck: New Jersey, 2006. 